Advances in Ecological Research, Vol 7, edited by J.B. Cragg. Academic Press, $€ 4$.

This latest volume in a valuable and well established series of reviews contains articles on heavy metal tolerance in plants (Antonovics, Bradshaw, and Turner), on plants of distinct photo-synthetic capacities (Black), on ecological aspects of fishery research (Gulland), and on the correlation of vegetation with recent climatic changes (Bray).

The article on metal tolerance is most welcome. The theoretical implications of the work, in demonstrating the rapidity of evolution in plants in response to environmental stress, are well summarised, but the section on the physiology of tolerance, the mechanisms by which tolerant plants survive, makes it clear that much research waits to be done. In addition the more practical aspects of this field, firstly in helping to identify areas of high metal contact for mining and later in reclaiming the mess consequent on the discovery, are clearly stated, so that the implications of the work for conservation are not difficult to see.

The second article discusses the physiological and biochemical data on which the evidence for dividing plants into those of low and those of high photosynthetic production capacity is based. The author rightly stresses the magnitude of the differences involved and briefly sketches the possible ecological implications. This is clearly a factor which ecologists will have to take greater account of when studying ecosystem processes.

Dr. Gulland's article on fishery research should be read by anyone interested in population structure and development, and in particular the effects of controlled cropping systems. He demonstrates the remarkably accurate predictions that can be made using mathematical models based on adequate field research. His work concerns the marine situation but the principles involved are widely applicable.

Finally, Dr Bray's discussion entitled 'Vegetational Distribution, Tree Growth, and Crop Success in Relation to Recent Climatic Change' summarises a fascinating body of evidence, including historical records and the existing vegetation patterns, and demonstrates the considerable changes that have been brought about by rather slight variations in climate. Particularly interesting are the sections on the 'little Ice Age' 3-400 years ago, which in Britain produced sufficient climatic deterioration to put an end to wine production, and on the very well documented changes that have occurred in the 20th century with consequent changes in crop growth patterns.

There can be few ecologists who will not find something of interest in this volume.

\title{
Wildlife was Best
}

ALASTAIR FITTER

Two interesting examples of the beneficial effects of wildlife where domestic animals were disastrous were described by Thane Riney recently speaking in Botswana. In north-eastern Botswana the introduction of borehole wells led to increases in the number of cattle which in turn led to depletion of the grass and the gradual drying-up of the permanent streams. In another area the shooting out of hippos had been the main cause of the drying-up of a river on which villages downstream depended, because the hippo trails had prevented the vegetation choking the water channels. He suggested that Botswana should preserve certain swamp lands in order to keep watersheds where crocodile farming should be practised. 